OPTIMIZATION OF PARAMETRES FOR WELDABILITY

STRENGTH - AN EXPERIMENTAL DESIGN APPROACH

\author{
C. LABESH KUMAR ${ }^{1}$, T. VANAJA $^{2} \&$ M. MAHENDER REDDY ${ }^{3}$ \\ ${ }^{1,2}$ Assistant Professor, Department of Mechanical Engineering, Institute of Aeronautical \\ Engineering, Dundigal, Hyderabad, India \\ ${ }^{3}$ Assistant Professor, Department of Mechanical Engineering, MLR Institute of
}

Technology, Dundigal, Hyderabad, India

\begin{abstract}
It is necessary to study the input parameters of welded product, to gain a 'welded joint' with good quality. The influence of welding parameters such as welding current, welding voltage and welding speed will show a significance effect on a welded joint. By using design of experiment method, the parameters can be optimized and made to have the best parameter combination for target quality. An orthogonal array, Signal to Noise(S/N) ratio have been employed to study the welding characteristics of material and optimize the welding parameter. The result has been computed using the form of contribution from each parameter, through which optimal parameters are identified for maximum tensile strength. The chosen parameters and obtained tensile strength results are analysed by using Minitab software, the calculations are done, results are generated and optimum results are obtained.
\end{abstract}

KEYWORDS: MIG Welding, Steel, Taguchi Technique, Tensile Strength \& MINITAB Software

Received: Jul 02, 2018; Accepted: Jul 23, 2018; Published: Sep 03, 2018; Paper Id.: IJMPERDOCT201827

\title{
INTRODUCTION
}

Metal Inert Gas (MIG) welding is well known and most widely used arc welding process in today's world. It is used to weld verity of materials, ferrous and non-ferrous. The weld quality of MIG welding largely depends on the various process parameters, viz. current, voltage, shielding gas flow rate, welding speed, wire feed rate, electrode angle, wire diameter, arc length etc. In the present investigation, effect of three important parameters; welding current, voltage and speed of weld are studied, and optimized for tensile strength of the weld. MIG arc welding is performed on low carbon steel and high carbon steel. An experiment has been designed using Taguchi L9 Orthogonal Array (OA) for the current study. For the selection of the input process parameters and their levels, various published literature were studied, and the already stated three parameters with three levels each were chosen.

\section{OBJECTIVE OF PRESENT WORK}

The objective of the present work is to investigate the effect of three important input parameters of MIG welding with two different materials i.e. low carbon and high carbon steel visible in different geometry; three parameters are current, voltage and weld speed are varied for welding to determine the Tensile Strength of joints, and to optimize the input parameters for maximum welding strength in tensile strength of weld. 


\section{METHODOLOGY}

To satisfy the above requirement, an experiment has been designed using Taguchi's experimental design technique. From various literature surveys, the following three factors with three levels each are selected as shown in TABLES for two different materials:

\section{Levels for Low Carbon Steel}

Table 1

\begin{tabular}{|l|c|c|c|}
\hline \multicolumn{1}{|c|}{ Parameters } & Level 1 & Level 2 & Level 3 \\
\hline Welding Current & 180 & 190 & 200 \\
\hline Welding Voltage & 23 & 25 & 27 \\
\hline Speed & 200 & 250 & 300 \\
\hline
\end{tabular}

Levels for Medium Carbon Steel

Table 2

\begin{tabular}{|l|c|c|c|}
\hline \multicolumn{1}{|c|}{ Parameters } & Level 1 & Level 2 & Level 3 \\
\hline Welding Current & 210 & 220 & 230 \\
\hline Welding Voltage & 24 & 26 & 28 \\
\hline Speed & 150 & 200 & 250 \\
\hline
\end{tabular}

Column Assignment of the Factors Orthogonal Array for Low Carbon Steel

Table 3

\begin{tabular}{|c|c|c|c|}
\hline Experiment & $\begin{array}{c}\text { Current } \\
\text { (amps) }\end{array}$ & $\begin{array}{c}\text { Voltage } \\
\text { (volts) }\end{array}$ & $\begin{array}{c}\text { Speed } \\
\text { (mm/min) }\end{array}$ \\
\hline 1 & 180 & 23 & 200 \\
\hline 2 & 180 & 25 & 250 \\
\hline 3 & 180 & 27 & 300 \\
\hline 4 & 190 & 23 & 250 \\
\hline 5 & 190 & 25 & 300 \\
\hline 6 & 190 & 27 & 200 \\
\hline 7 & 200 & 23 & 300 \\
\hline 8 & 200 & 25 & 200 \\
\hline 9 & 200 & 27 & 250 \\
\hline
\end{tabular}

Column Assignment of the Factors Orthogonal Array for Medium Carbon Steel

Table 4

\begin{tabular}{|c|c|c|c|}
\hline Experiment & $\begin{array}{c}\text { Current } \\
\text { (amps) }\end{array}$ & $\begin{array}{c}\text { Voltage } \\
\text { (volts) }\end{array}$ & $\begin{array}{c}\text { Speed } \\
\text { (mm/min) }\end{array}$ \\
\hline 1 & 210 & 24 & 150 \\
\hline 2 & 210 & 26 & 200 \\
\hline 3 & 210 & 28 & 250 \\
\hline 4 & 220 & 24 & 200 \\
\hline 5 & 220 & 26 & 250 \\
\hline 6 & 220 & 28 & 150 \\
\hline 7 & 230 & 24 & 250 \\
\hline 8 & 230 & 26 & 150 \\
\hline 9 & 230 & 28 & 200 \\
\hline
\end{tabular}




\section{MATERIAL AND SPECIMEN DRAWING OF MATERIALS}

\section{Low Carbon Steel}

Typically, this contains $0.04 \%$ to $0.30 \%$ carbon content. It is one of the largest groups of Carbon Steel. It covers a great diversity of shapes; from Flat Sheet to Structural Beam. Depending on the desired properties needed, other elements are added or increased.

Material Composition

Table 5

\begin{tabular}{|l|c|}
\hline \multicolumn{1}{|c|}{ Element } & Weight in \% \\
\hline Carbon & $0.14-0.20 \%$ \\
\hline Sulphur & $<0.05 \%$ \\
\hline Phosphorus & $<0.04 \%$ \\
\hline Manganese & $0.6-0.9 \%$ \\
\hline
\end{tabular}

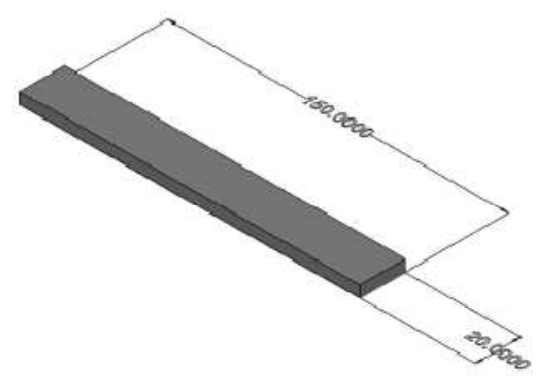

Figure 1: Specimen Drawing

\section{Medium Carbon Steel}

MCS steel typically has a carbon range of $0.31 \%$ to $0.60 \%$, and a manganese content ranging from $.060 \%$ to $1.65 \%$. This product is stronger than low carbon steel, and it is more difficult to form, weld and cut. Medium carbon steels are quite often hardened and tempered using heat treatment.

\section{Material Composition}

Table 6

\begin{tabular}{|l|c|}
\hline \multicolumn{1}{|c|}{ Element } & Weight in \% \\
\hline Carbon & $0.36-0.4400$ \\
\hline Silicon & $0.1-0.4$ \\
\hline Sulphur & $0.05 \mathrm{Max}$ \\
\hline Phosphorus & $0.05 \mathrm{Max}$ \\
\hline Manganese & $0.6-1.0$ \\
\hline
\end{tabular}

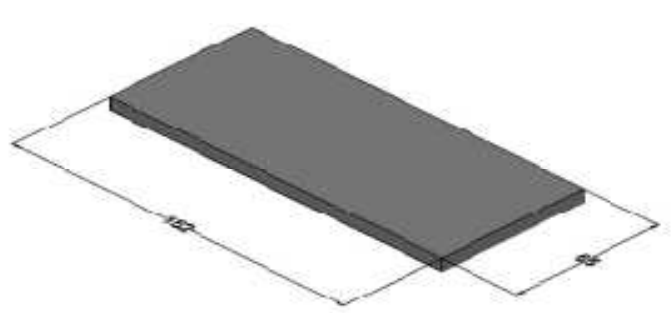

Figure 2: Specimen Drawing 
EXPERIMENTAL ANALYSIS AND RESULTS

Table 7: Tensile Values for the Low Carbon Steel

\begin{tabular}{|c|c|c|c|c|}
\hline S. No & Current & Voltage & Speed & Strength \\
\hline 1. & 180 & 23 & 200 & 28.75 \\
\hline 2. & 180 & 25 & 250 & 23.7 \\
\hline 3. & 180 & 27 & 300 & 26.4 \\
\hline 4. & 190 & 23 & 250 & 11.3 \\
\hline 5. & 190 & 25 & 300 & 39.5 \\
\hline 6. & 190 & 27 & 200 & 30.5 \\
\hline 7. & 200 & 23 & 300 & 25.75 \\
\hline 8. & 200 & 25 & 200 & 18 \\
\hline 9. & 200 & 27 & 250 & 33.5 \\
\hline
\end{tabular}

Table 8: Table Tensile Values for the Medium Carbon Steel

\begin{tabular}{|c|c|c|c|c|}
\hline S. No & Current & Voltage & Speed & Strength \\
\hline 1. & 210 & 24 & 150 & 67.5 \\
\hline 2. & 210 & 26 & 200 & 111.0 \\
\hline 3. & 210 & 28 & 250 & 52.0 \\
\hline 4. & 220 & 24 & 200 & 64.0 \\
\hline 5. & 220 & 26 & 250 & 84.0 \\
\hline 6. & 220 & 28 & 150 & 101.0 \\
\hline 7. & 230 & 24 & 250 & 97.5 \\
\hline 8. & 230 & 26 & 150 & 95.5 \\
\hline 9. & 230 & 28 & 200 & 68.0 \\
\hline
\end{tabular}

Obtained S/N RATIO for the Low Carbon Steel

Table 9

\begin{tabular}{|c|c|c|c|c|c|}
\hline S. NO & Current & Voltage & Speed & Strength & S/N Ratio \\
\hline 1. & 180 & 23 & 200 & 28.75 & 29.17 \\
\hline 2. & 180 & 25 & 250 & 23.7 & 27.49 \\
\hline 3. & 180 & 27 & 300 & 26.4 & 28.43 \\
\hline 4. & 190 & 23 & 250 & 11.3 & 21.06 \\
\hline 5. & 190 & 25 & 300 & 39.5 & 31.93 \\
\hline 6. & 190 & 27 & 200 & 30.5 & 29.68 \\
\hline 7. & 200 & 23 & 300 & 25.75 & 28.86 \\
\hline 8. & 200 & 25 & 200 & 18 & 25.10 \\
\hline 9. & 200 & 27 & 250 & 33.5 & 30.50 \\
\hline
\end{tabular}

Obtained S/N RATIO for the Medium Carbon Steel

Table 10

\begin{tabular}{|c|c|c|c|c|c|}
\hline S. NO & Current & Voltage & Speed & Strength & S/N Ratio \\
\hline 1. & 210 & 24 & 150 & 67.5 & 36.58 \\
\hline 2. & 210 & 26 & 200 & 111.0 & 40.90 \\
\hline 3. & 210 & 28 & 250 & 52.0 & 34.32 \\
\hline 4. & 220 & 24 & 200 & 64.0 & 36.12 \\
\hline 5. & 220 & 26 & 250 & 84.0 & 38.53 \\
\hline 6. & 220 & 28 & 150 & 101.0 & 40.08 \\
\hline 7. & 230 & 24 & 250 & 97.5 & 39.78 \\
\hline 8. & 230 & 26 & 150 & 95.5 & 39.60 \\
\hline 9. & 230 & 28 & 200 & 68.0 & 36.65 \\
\hline
\end{tabular}


Taguchi Analysis Graphs for Low Carbon Steel

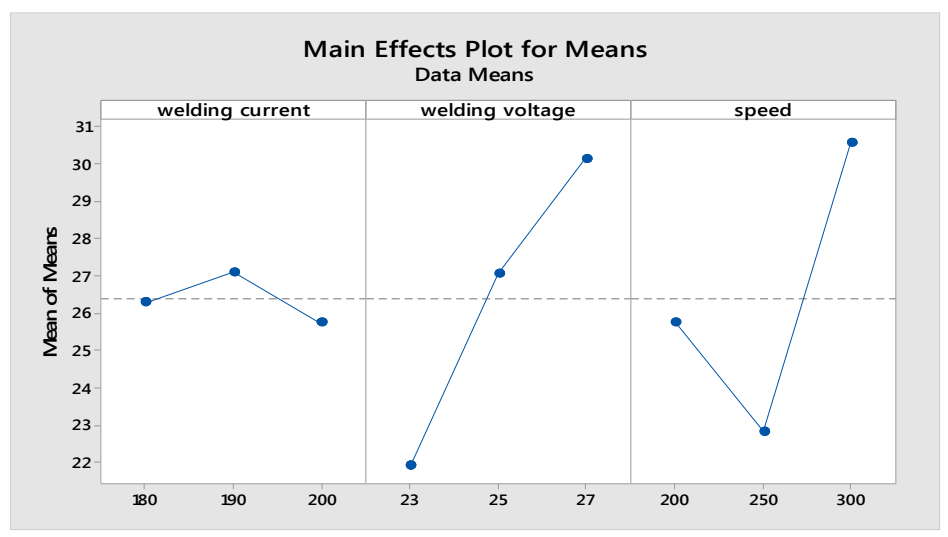

Figure 3: Main Effect Plot for Means for Low Carbon Steel

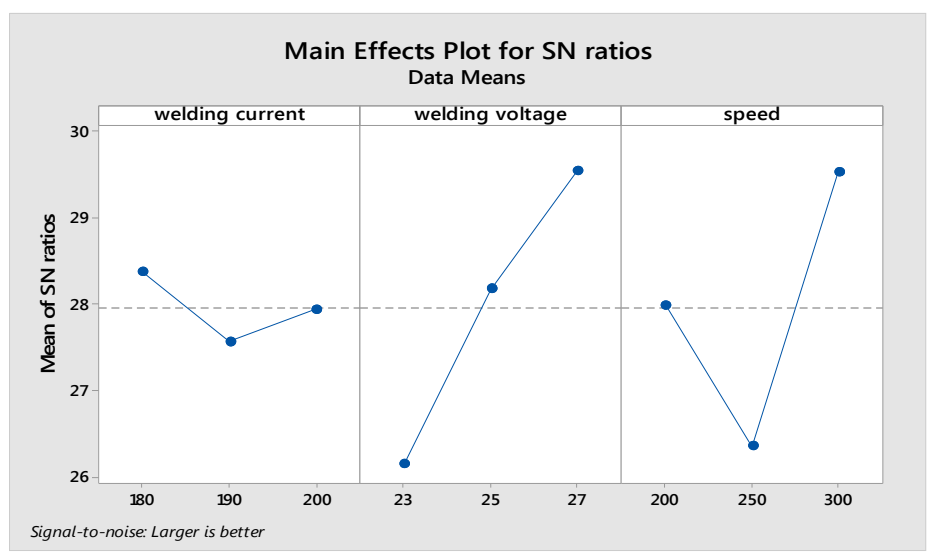

Figure 4: Main Effect Plot for S/N Ratio for Low Carbon Steel

The Figures obtained are plotted between means of all parameters individually, and $\mathrm{S} / \mathrm{N}$ ratio and all parameters, so that, the larger the better values, identified easily.

\section{Taguchi Analysis Graphs for Medium Carbon Steel}

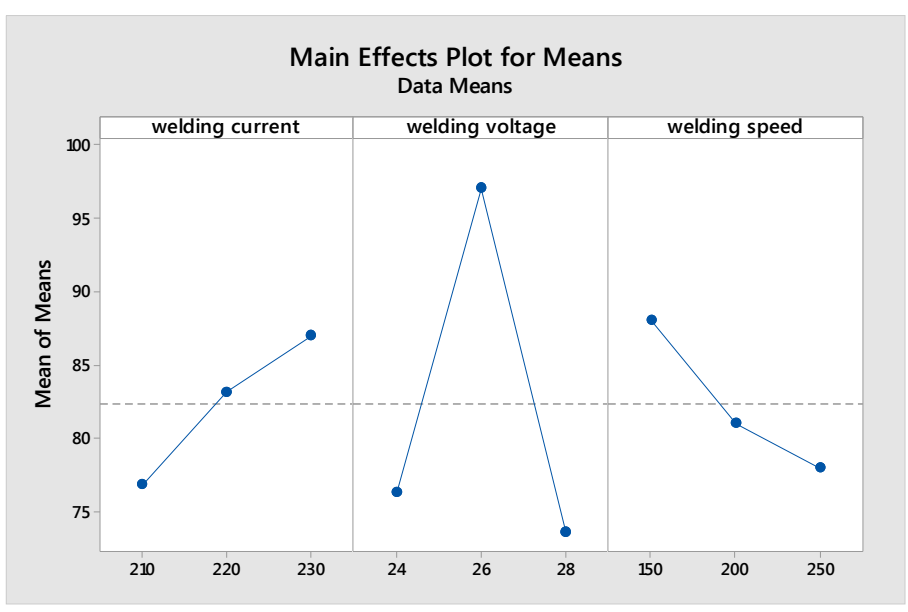

Figure 5: Main Effect Plot for Means for Low Carbon Steel 


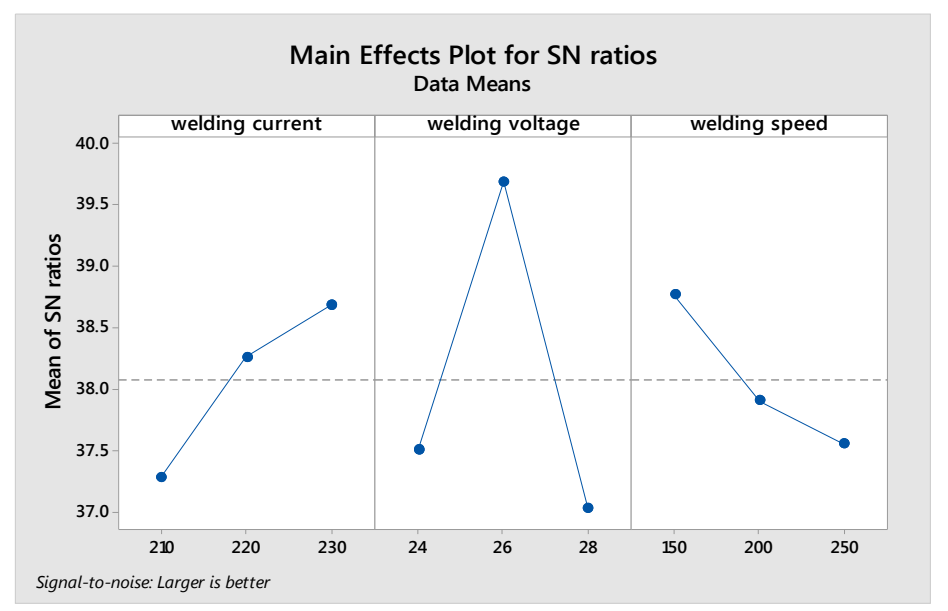

Figure 6: Main Effect Plot for S/N Ratio for Medium Carbon Steel

From the above figures, it is inferred that the highest point values between means and $\mathrm{S} / \mathrm{N}$ ratio to all individual parameters, are the optimal parameter values for welding.

\section{Response Table for Signal to Noise Ratios for Low Carbon Steel}

Larger is Better

Table 11: Values of Larger is Better Low Carbon Steel

\begin{tabular}{|c|c|c|c|}
\hline Level & Current & Voltage & Speed \\
\hline 1 & 28.37 & 26.15 & 27.99 \\
\hline 2 & 27.56 & 28.18 & 26.35 \\
\hline 3 & 27.94 & 29.54 & 29.53 \\
\hline DELTA & 0.81 & 3.39 & 3.17 \\
\hline RANK & 3 & 1 & 2 \\
\hline
\end{tabular}

\section{Response Table for Signal to Noise Ratios for Medium Carbon Steeel}

\section{Larger is Better}

Table 12: Values of Larger is Better Medium Carbon Steel

\begin{tabular}{|c|c|c|c|}
\hline Level & Current & Voltage & Speed \\
\hline 1 & 37.27 & 37.50 & 38.76 \\
\hline 2 & 38.25 & 39.68 & 37.89 \\
\hline 3 & 38.68 & 37.02 & 37.55 \\
\hline DELTA & 1.41 & 2.66 & 1.21 \\
\hline RANK & 2 & 1 & 3 \\
\hline
\end{tabular}

The above response table gives the result of parameter as up to what level, and which parameter effects the welding. Delta is the value of difference of higher value $\mathrm{S} / \mathrm{N}$ ratio to the second higher value of $\mathrm{S} / \mathrm{N}$ ratio, and rank is given according to the highest value obtained from ranking.

\section{CONCLUSIONS}

The optimization of parameters by the Taguchi's orthogonal array has proved to be an excellent tool. This experimentation has provided a significant result, by considering small experimentation values. The three parameters are contributing to the response, and all have been considered for experimentation of MIG welding. Among the parameters, the optimal parameters combination of Low Carbon Steel for higher tensile is speed 300mm/min, voltage 27 volts and 
current 180amps. Among the parameters, the optimal parameters combination of Medium Carbon Steel for higher tensile is speed $150 \mathrm{~mm} / \mathrm{min}$, voltage 26 volts and current $230 \mathrm{amps}$. The $\mathrm{S} / \mathrm{N}$ ratios of predicted values and verification test values are valid when compared with optimum values. The $\mathrm{S} / \mathrm{N}$ ratios are found to be within the limits of the predicted value, and the work has fulfilled the objective. Hence, it can be concluded that, the parameters are valid and within the range of the machining standards.

\section{REFERENCES}

1. C. Labesh kumar, Dr. CHV K N S N Moorthy, T. Vanaja and VVSH Prasad" 'Parametric Analysis For Improving Weld Strength Of Steel'. International Journal of Mechanical Engineering \& Technology (IJMET), Volume 8, Issue 8, August 2017, pp. 411-422, Scopus Indexed Journal.

2. Effect of arc voltage, welding current and welding speed on fatigue life, impact energy and bead penetration of AA6061 joints produced by robotic MIG welding by H. R. Ghazvinlool, A. Honarbakhsh-Raoufl and N. Shadfar.

3. A Review on Optimization of MIG Welding Parameters using Taguchi's DOE Method by Satyaduttsinh P. Chavdal, Jayesh V. Desai, Tushar M. Patel.

4. Effect of Mig welding input process parameters on weld bead geometry on HSLA steel by Mohd. Shoeb Department of Mechanical Engg R. D. Engg. College, Duhai Ghaziabad.

5. Optimization of Mig welding process parameters to predict maximum yield strength in AISI 1040 by AjitHooda, Ashwani Dhingra and Satpal Sharma.

6. Hand book by welding techniques - ESAB

7. Altamer A. de. (1980) 'Automatic welding and cladding in heavy fabrication', Journal of Metallurgical Construction.

8. Cary H. B. (1979) 'Modern Welding Technology'. New Jersey. Prentice Hall.

9. Chan B, Pacey J, Bibby M. (1999) 'Modeling gas metal arc weld geometry using artificial neural network technology'. Journal Of Canadian Metallurgical Quarterly

10. Majhi, B. P., \& Sahu, S. H. A. T. E. N. D. R. A. (2015). Optimization of machining parameters using bio-geography based algorithm technique. Int J Res Eng Technol,3, 9-18.

11. G. Haragopal, P V R Ravindra Reddy, G Chandra Mohan Reddy and J V Subrahmanyam, "Parametric design for MIG welding of Al-65032 alloy using Taguchi Technique”, Journal of Scientific and Industrial Research.

12. Amit Kohli and Hari Singh (2011) "Optimization of Processing Parameters in Induction Hardening Using Response Surface Methodology", Sadhana

13. Faseeulla Khan M D, Dwivedi D K and Satpal Sharma (2012), "Development of Response Surface Model for Tensile Shear Strength of Weld-Bonds of Aluminium Alloy 6061 T651", Materials and Design 
